\title{
Optimal sizing design of a 1.5 MW permanent magnets synchronous generator for an onshore wind conversion system
}

\author{
H. Gallas ${ }^{1,2}$, S. Le Ballois ${ }^{1}$, H. Aloui ${ }^{2}$ and L. Vido ${ }^{1}$ \\ ${ }^{1}$ SATIE Laboratory, SETE team, CY Cergy Paris University, Cergy-Pontoise, France \\ ${ }^{2}$ ESSE Laboratory, ISEM team, ENET’COM, Sfax, Tunisia
}

Phone : +33 (0) 134256902, e-mail : hayder.gallas@cyu.fr, sandrine.leballois@cyu.fr, helmi.aloui@enetcom.usf.tn. lionel.vido@cyu.fr

\begin{abstract}
This paper proposes a fast and accurate optimal sizing design of $1.5 \mathrm{MW}$ Permanent Magnets Synchronous Generator (PMSG) for a grid-connected wind application. A design strategy inspired from the output space mapping technique is adopted. A fast analytical model is used and detailed to determine the parameters and the performances of the PMSG. Then, the results are validated by a precise finite element model and adjusted iteratively until coherence between the two models is obtained. A multi-objective particle swarm optimization algorithm is deployed with aim of reducing the total losses and weight of the generator. The algorithm's parameters and results are given and analyzed. Three optimal machines are chosen and tested using a 2D-finite element model. The main design parameters of the optimal generators are given and discussed. Good efficiency and optimal designs are obtained for the sized machines thanks to the adopted design strategy.
\end{abstract}

Key words. Wind conversion systems, permanent magnets synchronous generator, analytical modeling, finite element method, optimization.

\section{Introduction}

The wind energy market has witnessed a remarkable expansion throughout the last two decades during which, the global installed wind capacity went from $24 \mathrm{GW}$ in 2001 to $651 \mathrm{GW}$ in 2019 [1]. Onshore large-scale wind conversion systems provide $95.4 \%$ of this capacity [1]. For this particular type of wind installations, permanent magnets synchronous generators (PMSG) have been established as one of the market's standards thanks to their good efficiency and high power density [2]. PMSG are used in both, direct-drive wind turbines (Type D) and gearbox-equipped ones (Type E) [3]. For the first type, a PMSG comes with an important number of pole pairs and thus, substantial dimensions and weight reduce its speed. For the second type, the size and the weight of the PMSG can be reduced thanks to the gearbox. This component is used to match the high speed of the generator with the low speed of the wind turbine's rotor [4]. Nevertheless, it is considered to be a vulnerable component and requires regular maintenance [5]. This comes with an additional cost especially for offshore wind farms. Thus, gearboxequipped turbines are mainly used for onshore applications offering the opportunity to use lighter and efficient generators. However, optimal design of the PMSG is a major factor to ensure the competitiveness of such an aerogenerator's topology compared to other technologies. This paper proposes an optimal sizing design for a 1,5 MW permanent magnets synchronous generator for a grid-connected wind conversion system (WCS).

The design of this generator for wind applications has been discussed in several papers. In [6], authors propose a complex multiphysics sizing model coupled to a deterministic algorithm for the design of a $55 \mathrm{~kW}$ PMSG for a direct-drive aerogenerator with the aim of reducing its cost. In [7], a geared PMSG is designed and compared to other architectures for a $5 \mathrm{MW}$ wind application with the aim of evaluating its annual energy production. In [8], authors presented an optimal design for a high voltage geared PMSG using an analytical design model combined to a genetic algorithm with aim of reducing its weight and cost. In [9], a small-scale PMSG is designed for direct-drive applications but no optimization was carried out. In these papers, all the design procedures were either complex and time-consuming to implement or conventional analytical methods with no further results validation.

The design strategy adopted in this work is inspired by the technique known as "output-space mapping" [10] (OSM). This technique is based on two models: a first simplified "coarse model" (usually analytical) used to calculate the parameters of the PMSG and a second "fine model" (usually a numerical finite element model) to verify and validate the outcomes of the first one. At each verification step, the gap between the parameters generated by each model is quantified with a coefficient. Then, this coefficient is used to adjust the results generated by the coarse model. This procedure is iterative until coherence between the two models is reached. Using the coarse model to calculate the parameters allows a fast calculation phase with minimum resources while the validation with the fine model ensures the precision of the obtained results. Thus, a fast and precise optimal sizing design can be reached.

In addition, to ensure high-fidelity results, a performant metaheuristic optimization algorithm [11] is chosen to calculate the optimal parameters of the PMSG. 
A multi-objective particle swarm optimization (MOPSO) [12] is set up with the aim of reducing the total losses and the weight of the PMSG.

The design specifications are given in the following section. In section 3 , the coarse analytical model is detailed and the magnetic submodel is validated using the numerical finite element method (fine model) of the PMSG. Finally, in section 4, the settings of the algorithm are detailed and the design results are given and analyzed.

\section{Design specifications}

A surface-mounted PMSG with distributed windings is considered in this work.

The machine is designed for the WindPACT Baseline 1.5 MW wind turbine [13]. This particular aerogenerator serves as a reference design in the context of the project "Wind Partnerships for Advanced Component Technology: WindPACT Advanced Wind Turbine Drivetrain Designs" [14]. This project, funded by the U.S. Department of Energy, introduced a set of wind turbines with the aim of reducing their overall cost and enhance their efficiency. Thus, the WindPACT Baseline 1.5 MW seems a good choice.

The PMSG should be designed according to geometric specifications. To fit in the nacelle of the adopted reference wind turbine, the machine should not exceed a maximum stator external radius $R_{\text {exts-max }}$ and axial active length $L_{a}$. The turbine's rotor has a rated speed of $20.5 \mathrm{rpm}$ with a gearbox ratio of 87.96 [13], thus the rated speed of the PMSG $\Omega_{b}$ and its rated power $P_{b}$ should be coherent with these parameters. Furthermore, as previously mentioned in section 1, a gearbox-equipped wind turbine comes with a smaller generator due to the fewer pole pairs $p$ it requires. Thus, regarding the rated speed of the wind turbine and the gearbox ratio, 6 pole pairs are considered. Another crucial factor in the design of such generators is the number of the stator slots $N_{s s}$. This parameter can be calculated as in (1) where $q$ is the number of phases (3 in our case) and $n_{s p q}$ is the number of slots per pole and per phase.

$$
N_{s s}=2 \cdot n_{s p q} \cdot p \cdot q
$$

The operating of the adopted PMSG depends directly on the choice of the parameter $n_{s p q}$ [15]. In fact, a low $n_{s p q}$ requires less stator windings and thus, ensures fewer copper losses. However, a higher $n_{s p q}$ will result in a better FEM's waveform and so will minimize torque ripples. As a result, this parameter should be chosen carefully.

In this work, minimizing the total losses is one of the design criteria and it will be handled by the optimization algorithm. Thus, the choice of the number of slots per phase and per pole should result in better waveforms. It was proven in [15] that an integer $n_{s p q}$ reduced the torque ripples of the generator. Besides, authors in [16] found that a value of 4 or 5 for $n_{s p q}$ resulted in good waveforms for a 2 MW PMSG. Hence, in this work, the total number of stator slots $N_{s s}$ is specified for 4 slots per phase and per pole.

Finally, two more electromagnetic design specifications are added, namely the maximum flux density of ferromagnetic materials $B_{f e r}$ and the maximum phase voltage $v_{a b c}$. The last one is derived from an advanced electromagnetic model developed in a previous work [17]. The design specifications discussed in this section are summarized in Table I.

Table I. - The PMSG's design specifications

\begin{tabular}{|l|c|c|}
\hline \multicolumn{1}{|c|}{ Parameter } & Symbol & Value \\
\hline Rated power & $P_{b}$ & $1.5 \mathrm{MW}$ \\
\hline Rated speed & $\Omega_{b}$ & $1800 \mathrm{rpm}$ \\
\hline Maximum phase voltage & $v_{a b c}$ & $3000 \mathrm{~V}$ \\
\hline Maximum flux density & $B_{\max }$ & $1.5 \mathrm{~T}$ \\
\hline Axial active length & $L_{a}$ & $250 \mathrm{~mm}$ \\
\hline Maximum Stator external radius & $R_{\text {exts-max }}$ & $2000 \mathrm{~mm}$ \\
\hline Number of pole pairs & $p$ & $6(-)$ \\
\hline Number of stator slots & $N_{s s}$ & $144(-)$ \\
\hline
\end{tabular}

\section{Multiphysics model}

As previously mentioned, first, an analytical coarse model is implemented. Then, it is validated using an accurate fine model. This latter one is a precise numerical model developed thanks to the finite element method using the Ansys Maxwell 2D/3D software [18]. This software tool is capable of solving transient and electromagnetic problems with accuracy thus, it is adopted.

The numerical model of the PMSG is also implemented using the design specifications given in Table I.

The coarse model is used to determine the necessary performances and electromagnetic parameters to simulate the transient behavior of the generator. Thus, it has been divided into two submodels namely, a magnetic submodel and an electric one.

\section{A. Magnetic submodel}

The purpose of this submodel is to reflect the magnetic behavior of the generator. In this work, it is used specifically to determine the no-load per phase flux linkage $\varphi_{v}$ and the flux density of the PMSG.

A reluctant network is necessary to calculate these parameters. The outcomes of this submodel are tested and validated through the numerical model before launching the optimization thus, some simplifying assumptions can be made to accelerate the modeling procedure. Therefore, a linear behavior of the inductances is assumed and no flux leakage components are considered. First, the distribution of the magnetic field lines is determined using the finite element model as given by Fig.1. Then, based on this distribution, a reluctant network is implemented as shown by Fig.2 with $R_{c \mathrm{r}}$ and $R_{c s}$ the reluctances of the rotor and the stator yokes, respectively, $R_{P M}$ the reluctances of the permanent magnets (PM), $R_{a}$ the reluctance of the air gap and $\varepsilon_{e}$ the magnetomotive force generated by the permanent magnets. 


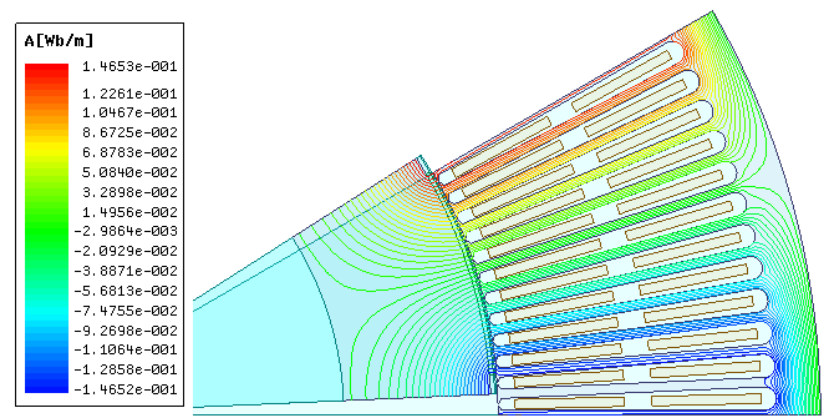

Fig. 1. Distribution of the magnetic field lines

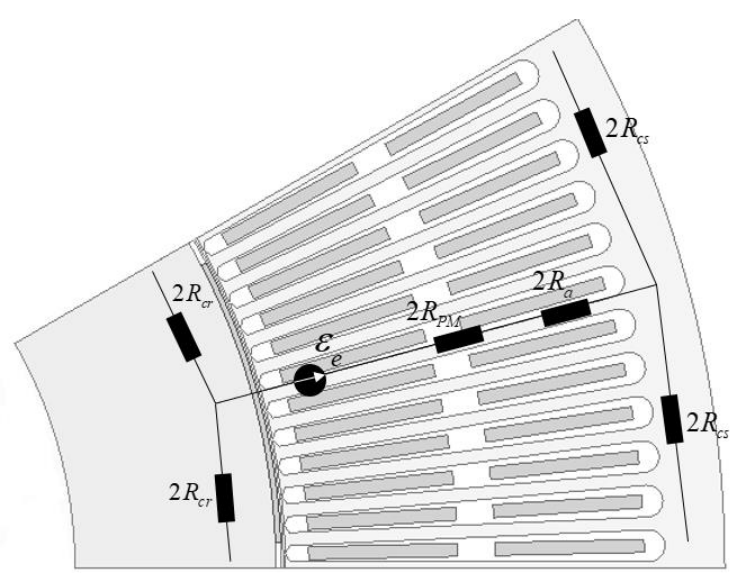

Fig. 2. The implemented reluctant network (RN)

M19 steel is used for the stator and rotor yoke and lamination. The relative permeability of this material can reach $500 \mathrm{H} / \mathrm{m}$ for a flux density of $1.6 \mathrm{~T}$ [19]. Thus, the reluctances $R_{c r}$ and $R_{c s}$ can be neglected. In addition, by observing Fig. 2, an axial symmetry can be noted. Thus, by application of the Thevenin Theorem, a simplified equivalent circuit of the reluctant network (Fig. 3) is used to calculate the no-load per phase flux linkage.

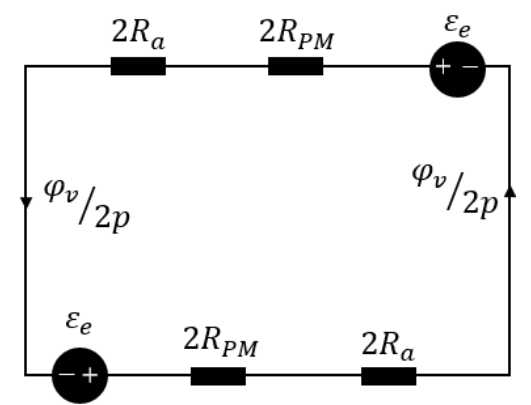

Fig. 3. Equivalent circuit of the simplified reluctances network

The flux linkage $\varphi_{v}$ as well as the different reluctances are calculated as follows:

$$
\begin{gathered}
\varphi_{v}=\frac{p \varepsilon_{e}}{R_{P M}+R_{a}} \\
R_{a}=\frac{e_{a}}{\mu_{0} L_{a} l_{a}} \\
R_{P M}=\frac{e_{P M}}{\mu_{0} \mu_{\mathrm{r}} S_{P M}}
\end{gathered}
$$

$$
\varepsilon_{e}=\frac{B_{P M} e_{P M}}{\mu_{0}}
$$

With $\mu_{0}$ the permeability, $l_{a}$ the air gap length over a pole pitch, $e_{a}$ the air gap thickness, $e_{P M}$ the PM thickness, $S_{P M}$ the PM surface and $\mu_{r}$ the relative permeability of the $\mathrm{NdFeB}$ (Neodymium) used for the PM.

Before using these equations to calculate the optimized parameters of the PMSG, the fine numerical model is used to validate it. The waveforms of the no-load flux linkage obtained by the finite element model (FE) and the reluctant network (RN) are given by Fig.4. As it can be observed, a sufficient similarity is obtained between the curves. Thus, the magnetic submodel is accurate enough to be used in the algorithm.

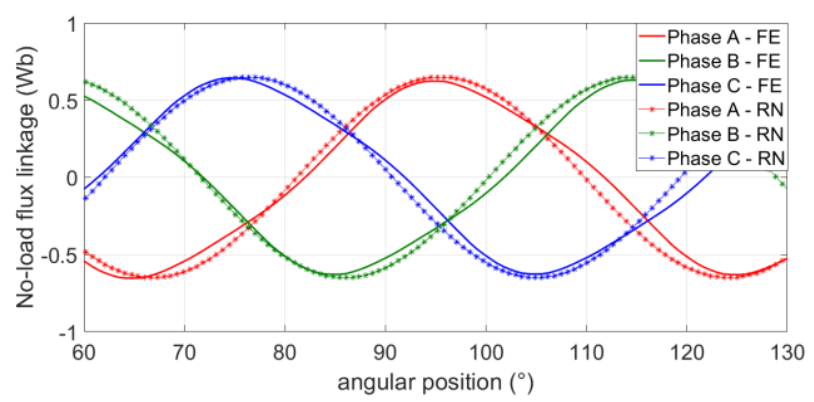

Fig. 4. Flux linkage evolution versus the angular position

\section{B. Electric submodel}

In this subsection, the analytical equations of the PMSG are used to calculate its electromagnetic parameters and performances.

These parameters are calculated at a specific operating point where the electromagnetic torque, the phase voltages and currents are maximum. This point should reflect the rated operating of the PMSG. Thus, it is chosen.

The considered PMSG is a non-salient pole machine. Therefore, no cogging torque is considered. The electromagnetic torque $T_{e m}$ is then expressed as a function of the flux linkage $\varphi_{v}$ as in (6) with, $J_{s}$ the current density and $S_{c u}$ the copper section per winding.

$$
T_{e m}=3 p \varphi_{v} J_{s} S_{c u}
$$

For distributed windings, which is the case, the copper section $S_{c u}$ can be calculated as given in (7) with, $t_{f}$ the ratio of the iron compared to the copper at the winding, $R_{s s}$ the stator slots radius and $R_{\text {ints }}$ the stator internal radius.

$$
S_{c u}=\frac{\pi\left(1-t_{f}\right)\left(R_{s s}^{2}-R_{\mathrm{ints}}^{2}\right)}{6 p n_{s p q}}
$$

Using both equations, (6) and (7), the current density $J_{s}$ is calculated. Then, its quadratic and direct components $J_{q}$ and $J_{d}$ are used to calculate the output DC-bus voltage of the generator $v_{d c}$. Now, it should be noted that for a non- 
salient pole machine, the permeances of both axis $P_{d}$ and $P_{q}$ are equal and thus, $v_{d c}$ can be expressed as in (8)

$$
\begin{aligned}
& v_{D C}=n \cdot \sqrt{\left(r_{s} \cdot J_{q} \cdot S_{c u}+J_{d} \cdot x_{1}+\sqrt{3} \cdot \varphi_{v}\right)^{2}} \\
& \text { with } \\
& \left.x_{1}=\Omega_{b} \cdot \mathcal{P}_{d} \cdot S_{c u} \cdot S_{c u}-J_{q} \cdot x_{1}\right)^{2}
\end{aligned}
$$

The number of turns per coil $n$ can be expressed as in (9) with, $K_{b}$ the winding factor. As for $r_{s}$, it is defined to model the Joule losses at the stator windings. It is expressed as in (10) with, $\rho_{c u}$ the copper resistivity and $k_{\text {remp }}$ the copper filling ratio at the stator windings.

$$
\begin{gathered}
n=\frac{v_{a b c}}{4.44 f \cdot K_{b} \cdot \varphi_{v}} \\
r_{s}=\rho_{c u} \frac{l_{c u}}{n_{s p q} \cdot k_{r e m p} \cdot S_{c u}}
\end{gathered}
$$

Finally, as mentioned in section 1, minimizing the total losses of the machine is one of the optimization objectives. The total losses are the sum of the Joule losses $P_{j}$, the aerodynamic losses $P_{\text {aero }}$ and the iron losses $P_{f \text {. The output }}$ power $P_{\text {out }}$ can be expressed as in (11) and the efficiency at rated operating $\eta$ is expressed as in (12).

$$
\begin{gathered}
P_{\text {out }}=P_{b}-\sum P_{j}+P_{\text {aero }}+P_{f} \\
\eta=\frac{P_{b}}{P_{\text {out }}}
\end{gathered}
$$

\section{Optimization}

The metaheuristic algorithm "particle swarm optimization" is adopted in this work. To understand its working mechanism, let $i$ be a particle effecting a movement in the state space $t$. This particle is characterized by a position vector and a velocity vector. When moving, $i$ keeps in memory its best personal experience over the state space. The particle $i$ moves in a group of particles. The group's best experience is also kept in memory as a global best. The search is then guided by these two parameters, the personal experience of the particle $i$ and the global experience of the group. These movements are iterative until reaching the global optimum of the search space. Thus, the risk of converging to a local sub-optimum is extremely minimized.

\section{A. Optimization variables}

The aim of this optimization is to reduce the total weight $m_{t}$ and the losses $P_{t}$ of the PMSG. In this work, the weight of the generator is the sum of the weight of the steel $m_{s}$, the copper used for the windings $m_{c u}$ and the total weight of the permanent magnets $m_{P M}$.

The geometric optimization parameters are summarized in Table II.
Table II. - The PMSG's design specifications

\begin{tabular}{|l|c|}
\hline \multicolumn{1}{|c|}{ Parameters } & Symbol \\
\hline Magnet thickness & $e_{P M}$ \\
\hline Air gap thickness & $e_{a}$ \\
\hline Stator slots length & $l_{S S}$ \\
\hline Stator slot height & $h_{S s}$ \\
\hline Shaft radius & $R_{S h}$ \\
\hline Rotor external radius & $R_{\text {extr }}$ \\
\hline Number of turns per coil & $n$ \\
\hline
\end{tabular}

The adopted multi-objective particle swarm optimization [20] is set to stop after 400 generations. At each generation, 100 iterations are performed. At each iteration, the calculated parameters are verified according to the design criteria.

\section{B. Optimization criteria}

Two types of optimization criteria are adopted. The first one is a global criterion imposed by the design specifications given in Table I. namely, the maximum stator external radius $R_{\text {exts-max }}$. In addition, five local criteria are imposed as follows:

- The current density $J_{s}$ should not exceed a maximum value $J_{\max }$. This value is calculated using equation (6) for a maximum electromagnetic torque $T_{e m-\max }$ of -7942 N.m calculated for the rated power $P_{b}$ at the rated speed $\Omega_{b}$.

- The DC-bus voltage generated by the machine should not exceed a maximum DC-bus voltage of $800 \mathrm{~V}$ [21].

- Three criteria are added concerning the maximum flux density of the PMSG. The flux density at the stator yoke $B_{s y}$, at the rotor yoke $B_{r y}$ and at the stator slots $B_{s s}$ should not exceed the maximum value $B_{\max }$.

Finally, a mathematical formulation of the considered optimization problem can be given as in (13).

$$
\left\{\begin{array}{l}
\min f_{1}\left(x_{1}\right) \underset{x_{1} \in\left\{P_{j}, P_{f}, P_{\text {aero }}\right\}}{=} \min P_{t}\left(x_{1}\right) \\
\min f_{2}\left(x_{2}\right)_{x_{2} \in\left\{m_{c u}, m_{s}, m_{P M}\right\}}^{=} \min m_{t}\left(x_{2}\right) \\
\text { with: } \\
R_{s t a t o r} \leq R_{\text {exts-max }} \\
J_{\max } \leq 17.5 \cdot 10^{4} \mathrm{~A} / \mathrm{m}^{2} \\
V_{d c \max } \leq 800 \mathrm{~V} \\
B_{s y} \leq B_{\max } \\
B_{r y} \leq B_{\max } \\
B_{s s} \leq B_{\max }
\end{array}\right.
$$

\section{Optimization results}

The results generated by the algorithm are based on the coarse model. To ensure the precision, the optimal machines are then tested using the fine 2-D finite element model. 
Following the mechanism of the adopted optimization technique, after each verification, an adjustment coefficient is calculated. Then, it is introduced into the coarse model until adequacy is achieved between the results generated by both models.

The optimized machines should have a torque that is equivalent to the maximum rated one, $T_{e m-\max }$. Therefore, the adjustment coefficient is calculated to quantify the difference between the two values. Based on equation (6), the torque's analytical model is a function of the no-load flux per phase $\varphi_{v}$ and of the current density $J_{s}$. The no-load flux is already validated by the fine element as proven by Fig. 4. Thus, the adjustment coefficient is applied to the current density.

The first execution of the algorithm resulted in 100 machines. The verification carried out using Ansys maxwell, showed a torque that varies between -1500 N.m and -6000 N.m. The adjustment coefficient is calculated for the lowest torque obtained and the algorithm is reexecuted iteratively, after rectification.

The adequacy between the coarse model and the fine model is obtained after three iterations. The Pareto Front for 100 optimal designs is given by Fig. 5 .

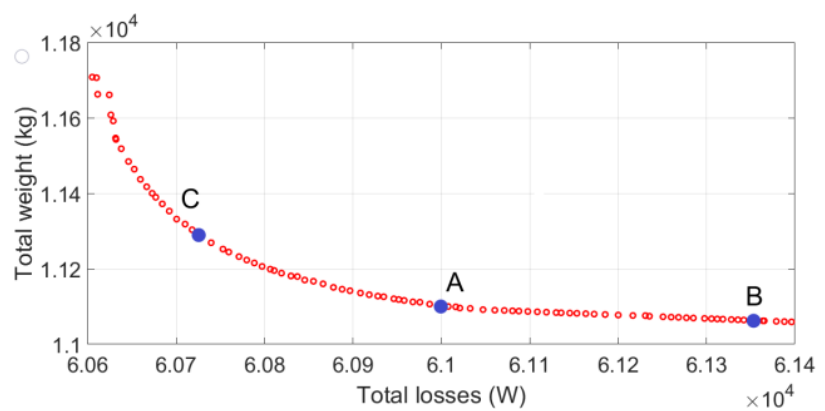

Fig. 5. Pareto front total losses versus total weight

All the points given by Fig. 5 are solutions for the considered optimization problem described by (13). The Utopia point is chosen as the machine A with the best compromise between losses and weight. Machine A presents the best solution. However, two more machines are also chosen namely, machine $\mathrm{B}$ with the minimum weight and machine $\mathrm{C}$ with the lowest losses. The main design parameters of the chosen machines are summarized in Table III.

Table III. - The PMSG's design specifications

\begin{tabular}{|l|c|c|c|}
\hline \multicolumn{1}{|c|}{ Parameters } & A & B & C \\
\hline Stator external radius (mm) & 1728.9 & 1725.3 & 1731.4 \\
\hline Rotor external radius (mm) & 1161.6 & 1172.7 & 1161.6 \\
\hline PM thickness (mm) & 13.6 & 13.6 & 13.6 \\
\hline Number of turns per coil & 2 & 2 & 2 \\
\hline Stator yoke thickness (mm) & 2,7 & 2,6 & 5,4 \\
\hline Air gap thickness (mm) & 1 & 1 & 1 \\
\hline Torque (N.m) & -8008 & -8196 & -7995 \\
\hline Rated efficiency (\%) & 95.93 & 95.9 & 95.95 \\
\hline Total weight $(\mathrm{kg})$ & 11102 & 11059 & 11232 \\
\hline Total losses $(\mathrm{kW})$ & 61 & 61.4 & 60.7 \\
\hline
\end{tabular}

For machine A, the no-load flux linkage is given by Fig. 6 . As it can be seen, similar waveforms and maximum value obtained with electromagnetic submodel are also obtained with finite element model of machine A.

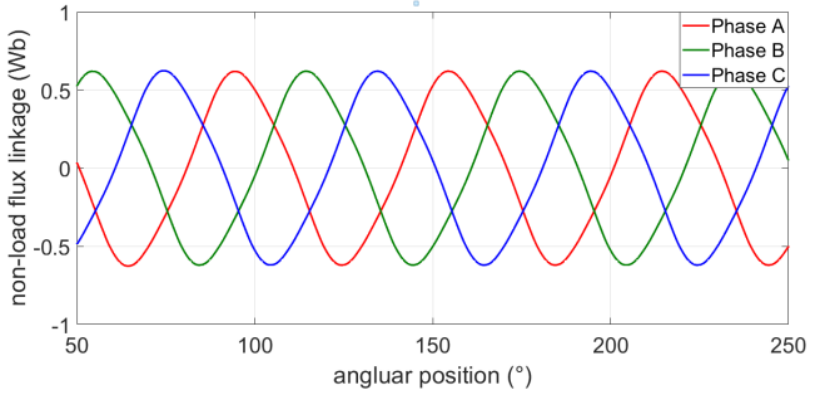

Fig. 6. Flux linkage evolution - machine A

The electromagnetic torque, the phase currents and the induced phase voltages are given by Figures 7, 8 and 9, respectively. As it can be noticed, the torque is at its optimal value $T_{\text {em-max }}$ with minimum ripples and smooth waveforms are obtained for the windings current and the induced voltages with respect to the specified maximum values.

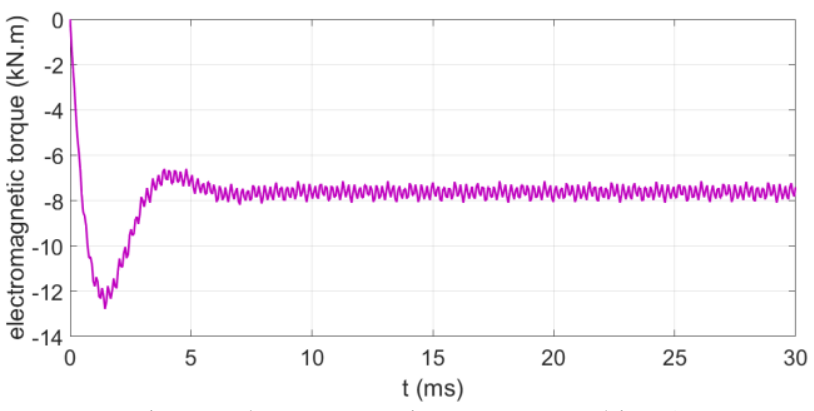

Fig. 7. Electromagnetic torque - machine A

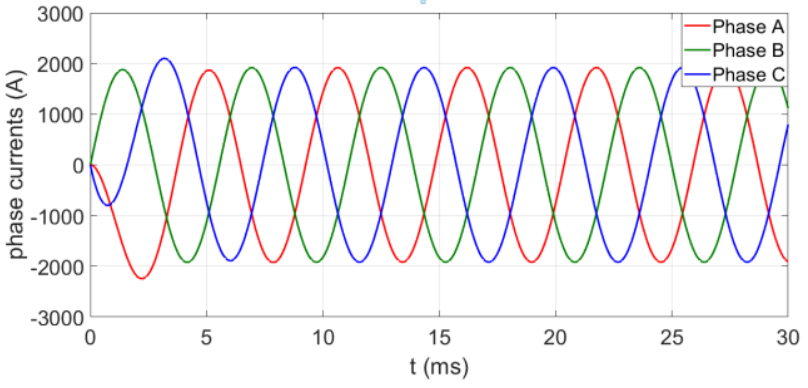

Fig. 8. Windings currents per phase - machine A

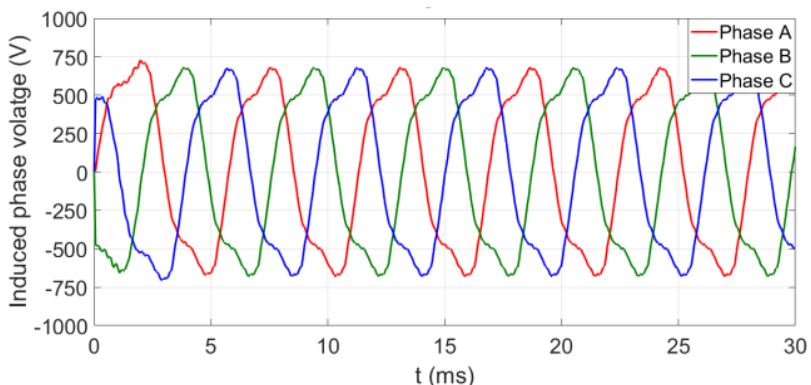

Fig. 9. Induced voltage per phase - machine A

In terms of comparison, two direct-drive permanent magnet synchronous generators were designed in [21] for the WindPact Baseline 1.5 MW wind turbine. The first one is a spoked arm-Type PMSG with a total weight of $27920 \mathrm{~kg}$ and an efficiency of $93 \%$. The second one is a 
Disc-Arm-Type PMSG with a total weight of $30630 \mathrm{~kg}$ and an efficiency of $93.19 \%$. In this work the designed generator comes with a total weight of around $11000 \mathrm{~kg}$. Although this is quite normal for a gearbox-equipped PMSG to be lighter, a better efficiency of $96 \%$ is obtained in this work compared to the results published in [21] where an efficiency of $93 \%$ is obtained.

This shows the performances of the adopted optimization technique to conduct the optimal sizing design of the 1.5 MW PMSG.

\section{Conclusion}

In this paper, an optimal sizing design of a 1.5 MW Permanent Magnets Synchronous Generator (PMSG) is conducted. The PMSG is designed to operate for the WindPact Baseline 1.5 MW reference wind turbine. To avoid complex multiphysics models and time-consuming finite element sizing, a strategy inspired from the output spacing mapping technique is adopted. First, the machine is modeled using a fast analytical model. A reluctant network is developed and a set of analytical equations are implemented to calculate the PMSG's parameters. Then, a finite element model is used to validate the results. The validation procedure is iterative until results generated by both models are similar. Thus, precision is ensured while using a fast and simple analytical sizing model. The optimization is carried out with the aim of reducing the total losses and weight of the generator. A powerful metaheuristic particle swarm optimization is adopted to ensure that a global optimal is found. The Pareto front is then plotted and three machines are chosen namely, the one with the best compromise between losses and weight, the machine with the lowest losses and the machine with the minimum weight. The main design parameters and performances are given for the three machines.

Finite element validation results show a good efficiency and smooth waveforms for the optimally designed machines.

\section{References}

[1] GWEC (2019), Global wind report 2019, Global Wind Energy Council.

[2] F. Blaabjerg, F. Iov, Z. Chen and K. Ma, "Power electronic and controls for wind turbine systems", 2010 IEEE International Energy Conference, Manama, pp. 333-344.

[3] A.D. Hansen and L.H. Hansen, "Wind turbine concept market penetration over 10 years (1995-2004)", Wind Energy 2007, vol. 10, no .1, pp. 81-97.

[4] C. Vázquez-Hernández, J. Serrano-González and G. Centeno, "A Market-Based Analysis on the Main Characteristics of Gearboxes Used in Onshore Wind Turbines", Energies 2017, vol. 10, no 11, pp. 1686.

[5] R. F. M. Brandão, J. A. B. Carvalho and F. P. M. Barbosa, "Forecast of faults in a wind turbine gearbox", ELEKTRO 2012, IEEE, pp. 170-173

[6] T. de Paula Machado Bazzo, J. F. Kölzer, R. Carlson, F. Wurtz and L. Gerbaud, "Multiphysics Design Optimization of a Permanent Magnet Synchronous Generator", IEEE Transactions on Industrial Electronics 2017, vol. 64, no. 12, pp. 9815-9823.
[7] H. Polinder, F. F. A van der Pijl, G. J. de Vilder, and P. Tavner, "Comparison of Direct-Drive and Geared Generator Concepts for Wind Turbines," IEEE Trans. Energy Conversion 2006, vol. 21, pp. 725-733.

[8] A. D. Lilla, H. Dehnavifard, M. A. Khan and P. Barendse, "Optimization of high voltage geared permanent-magnet synchronous generator systems", International Conference on Electrical Machines (ICEM), Berlin, 2014, pp. 13561362.

[9] A.P. Ferreira, A.F. Costa, Direct Driven Axial Flux Permanent Magnet Generator For Small-Scale Wind Power Applications, International Conference On Renewable Energies And Power Quality, Las Palmas de Gran Canaria (Spain), 2010.

[10] J. W. Bandler, R. M. Biernacki, Shao Hua Chen, P. A. Grobelny and R. H. Hemmers, "Space mapping technique for electromagnetic optimization", IEEE Transactions on Microwave Theory and Techniques 1994, vol. 42, no. 12, pp. 2536-2544.

[11] A. Hanif Halim, I. Ismail and S. Das, "Performance assessment of the metaheuristic optimization algorithms: an exhaustive review", Artificial Intelligence Review 2020, pp. 1-87.

[12] D. Kaczorowska, J. Rezmer, T. Sikorski and P. Janik, Application of PSO algorithms for VPP operation optimization, Renew. Energy Power Qual. J. 17 (2019) 91-96. doi:10.24084/repqj17.230.

[13] K.L. Dykes and J. Rinker, "Windpact reference wind turbines", NREL /TP-5000-67667, National Renewable Energy Lab (NREL), Golden, CO, United States, 2018.

[14] Wind Partnerships for Advanced Component Technology, "WindPACT Advanced Wind Turbine Drivetrain Designs", Northern Power Systems, Inc, United States.

[15] C. Tang, W. L. Soong, G. S. Liew and N. Ertugrul, "Effect of pole and slot number changes on the performance of a surface PM machine", XXth International Conference on Electrical Machines 2012, Marseille, pp. 220-227

[16] T. Liu, S. Huang, Q. Deng, Q. Pu and K. Huang, "Effect of the number of slots per pole on performance of permanent magnet generator direct-driven by wind turbine," 2011 International Conference on Electrical Machines and Systems, Beijing, 2011, pp. 1-4, doi: 10.1109/ICEMS.2011.6073738.

[17] H. Gallas, S. L. Ballois, H. Aloui and L. Vido, "Robust Control and Harmonics Modeling of a PMSG for a 1.5 MW Wind Turbine," International Conference on Electrical Machines (ICEM) 2020, Gothenburg, Sweden, pp. 305-311.

[18] ANSYS Maxwell, February 2019, [online] Available: https://www.ansys.com/products/electronics/ansysmaxwell.

[19] N. A. M. Rashid and W. Mahadi, "Simulation and Statistical Approaches on Electrical Steel's Magnetic Behavior under Unidirectional Single Sheet Tester", Sains Malaysiana, 2014, vol. 43, no. 6, pp. 909-914

[20] J. Kennedy and R. Eberhart, "Particle swarm optimization", Proceedings of ICNN'95 - International Conference on Neural Networks, Perth, WA, Australia, 1995, vol. 4, pp. 1942-1948.

[21] L. Sethuraman, and K.L. Dykes, "GeneratorSE: A Sizing Tool for Variable-Speed Wind Turbine Generators", No. NREL/TP-5000-66462. National Renewable Energy Lab.(NREL), Golden, CO United States, 2017. 